\title{
After all, everybody loves a good story! Update on the Case Reports' Chronicle
}

\author{
R. Trisolini
}

Monaldi Arch Chest Dis 2011; 75: 4, 205-206.

Thoracic Endoscopy and Pulmonology, Maggiore Hospital, Bologna, Italy.

Correspondence: Rocco Trisolini, MD; Thoracic Endoscopy and Pulmonology Unit, Maggiore Hospital, Largo Nigrisoli 2, 40133 Bologna,Italy; e-mail: rocco.trisolini@ausl.bologna.it

In the era of evidence-based medicine, case reports are regarded as being at the bottom in the hierarchy of scientific evidence and have suffered a huge crisis [1]. Their main limit, which is inherent to the study design, is that they cannot be generalised beyond the context of the specific patient being described. Additional drawbacks, such as frequent lack of sufficient clinical novelty and minimal influence on a journal's impact factor due to their low-citation rate [2], have further reduced, over time, their appeal to the major medical journals, which have either markedly reduced the room for case reports in their classic format or no longer publish this study design.

On other hand, patient case reports are an essential vehicle of information to the medical world for several reasons. First, they are a foundation for experimental research. All science, including medicine, is rooted in observations, and clinicians are in the ideal position to observe unusual cases, develop rational explanations for the findings, and verify if experimental research validates or confutes their hypotheses. Second, case reports are almost always the means by which authors get started in medical writing. I do still remember the thrill when Maurizio Luisetti, my mentor and incidentally my predecessor as Editor handling case reports at Monaldi [3], asked me to try and write my first case report back in 1998 [4]. That exercise made me face, either for the first time or from a different viewpoint, problems such as concise written communication, thorough analysis of a topic, and critical thinking. In the end, the publication of that first paper made me proud, and made me understand that I could be play a part, albeit a small one, in the world of clinical research. However, the merit that helped most case reports make it through their own crisis is the simple fact that they represent a successful and charming way to teach medicine. Students and practitioners, in fact, learn best to apply new knowledge when it is presented in the form of an experience they are likely to encounter in clinical practice. Medicine is all about approaching a problem, and one can apply the approach used in a case report to his/her practice. To meet this strong need for practical and educational information, several journals have very recently modified or widened the format of case reporting they consider for publication by including, among the others, images-based formats $[5,6]$, question and answer formats [7,8], clinical-pathological conferences [9, 10], and clinical problem-solving formats [11]. In the end, this chameleontic adaptation to the real-life medicine needs has allowed case reporting not only to survive its crisis, but to regain most of the room it had lost in the past decades in many core journals.

Monaldi, that has always given a higher value to education and teaching than achieving an 'impact factor', has never given up case reports, and has been attentive to the changes in medical publishing.

With the swift development of several new and powerful diagnostic methods, physicians are observing astonishing or unusual images of common medical conditions. In most such cases, the image is the only finding worthy of publication in a patient's case, and this is the reason why the Editorial Board at Monaldi has recently announced a new images-based format ("Images of Chest Diseases") where the image(s) should be submitted with a brief commentary (300 words at the most, see instruction for authors) [12].

We do still look forward to receiving case reports in the classic format, but we need to make a qualitative step forward. So, what virtues do we value most in a case report? Uniqueness is certainly the characteristic of the subject matter that more commonly makes it potentially worth describing, since new findings are more likely to establish new principles or modify currently accepted concepts [1]. An unusual feature of a known condition, an undescribed complication of a procedure/drug, a different or a more cost-effective approach to the diagnosis or the treatment of a given disease may still meet the criterion of uniqueness for our journal, as we all know that only few clinicians have the opportunity to encounter and recognise a disease or a syndrome that is completely new. However, what we most need is brief reports where the lesson taught by 
the case is clearly conveyed. Brevity and clarity are, in fact, characteristics of the manuscript that are invaluable to the reader, whose attention should remain focused on the path that finally leads to the key message the Authors want to convey, and should not get lost in unnecessary details and unrelated to the topic described. Unfortunately, writing a succinct yet complete report is far more difficult than preparing a lengthy manuscript, and I was not surprised by the fact that the lack of brevity and clarity was, by far, the most common flaw limiting the efficacy and interest of case reports submitted for publication at Monaldi in the past few years. Some methodological tips, which are beyond the scope of this Editorial, may certainly be of great help for authors who want to get started in scholarly writing with case reports $[13,14]$. We also can do something. It is a largely shared opinion, for instance, that an unusual or unreported feature, complication, intervention or management approach can be described accurately in less than 1000 words in most cases [1]. Accordingly, and in the interest of the readers and the authors themselves, we have decided to set new formatting rules for case reports to be submitted for publication at Monaldi in the near future, one of them being an 800 word limit for the text (see Instruction for Authors).

The Editorial Board at Monaldi intends to confirm and strengthen the journal's continued commitment to case reporting and invites physicians to be always on the look out for unusual cases and to describe them in a report. After all, everybody loves a good story!

\section{References}

1. Soffer A. The crisis of case reports. Chest 1971; 59: 244.

2. Patsopoulos NA, Analatos AA, Ioannidis JPA. Relative citation impact of various study design in health sciences. JAMA 2005; 293: 2362-6.

3. Luisetti M. Case reports in Monaldi: eleven years so far and a continuing commitment. Monaldi Arch Chest Dis 2004; 61: 2, 80 .

4. Trisolini R, Dore R, Bertolini R, et al. Longstanding endobronchial foreign body. Diagn Ther Endosc 1999; 5: 257-61.

5. Xiong W, Shi C. Malignant pericardial effusion. N Engl J Med 2011; 364: e18.

6. Trisolini R, Giovannitti A, Patelli M. Tracheal flap after dilatational percutaneous tracheostomy. Anesthesiology, accepted for publication.

7. Anevlavis S, Cancellieri A, Livi V, Patelli M, Trisolini R. A 66-year-old woman with cough and exertional dyspnea. Chest, accepted for publication.

8. Trisolini R, Cancellieri A, Forti Parri S, Burzi M, Boaron M, Patelli M. A very unusual case of pulmonary consolidation diagnosed by transbronchial needle aspiration. Respiration 2009; 78: 334-8.

9. Kheir F, Simeone F, Johnston S, Shackelford R, Lasky J. An 11-year-old boy with respiratory failure and massive pleural fluid drainage. Chest 2011; 140: 1659-61.

10. Senecal EL, Rosenfield K, Caldera AE, Passeri JJ. A 93-year-old woman with shortness of breath and chest pain. N Engl J Med 2011; 365: 2021-8.

11. Leigh Miller A, Shissel S, Levy BD, Loscalzo J. A crazy cause of dyspnea. N Engl J Med 2011; 364: 72-7.

12. Editorial Board. Images of chest diseases: a new format for case reports in Monaldi. Monaldi Arch Chest Dis 2011; 75: 146.

13. Cohen H. How to write a patient case report. $A m J$ Health-Syst Pharm 2006; 63: 1888-92.

14. Green BN, Johnson CD. How to write a case report for publication. J Chiropr Med 2006; 5: 72-82.

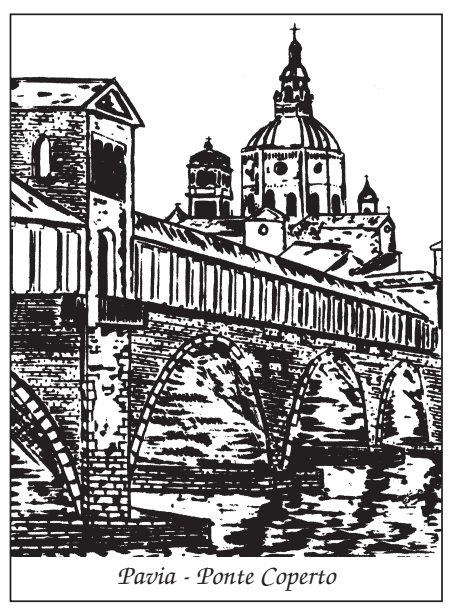

